\title{
Erratum: Free-decay and resonant methods for investigating the fundamental limit of superhydrophobicity
}

\author{
Jaakko V.I. Timonen, Mika Latikka, Olli Ikkala \& Robin H.A. Ras
}

Nature Communications 4:2398 doi: 10.1038/ncomms3398 (2013); Published 12 Sep 2013; Updated 24 Jan 2014

There were errors associated with the Supplementary Movies in the version of this Article originally published, which were introduced while the HTML was being prepared. The titles of Supplementary Movies 1, 2 and 3 were incorrectly linked to Supplementary Movies 2, 3 and 1, respectively, and the legends were omitted. These errors have now been corrected in the HTML version of the Article; the PDF was correct from the time of publication. 